\title{
Descriptive Geometry and Spatial Ability-Correlation and Mutual Impact at Engineering Students
}

\author{
Maja ILIĆ*, Sandra KOSIĆ-JEREMIĆ, Milena STAVRIĆ
}

\begin{abstract}
Spatial abilities are recognized as one of the main factors for success in technical (STEM) professions, especially in the field of architecture and civil engineering. Given that this kind of competence is not paid enough attention to in the early stages of education, students arriving at technical faculties have difficulties in mastering the subject of Descriptive geometry and solving spatial problems in general. There are different opinions on whether these abilities are inborn, if they could be improved and if they could, in what way. In this paper, the relation between spatial abilities and the subject of Descriptive geometry at the University of Banja Luka will be examined. The study involved 175 first-year students of the Faculty of Architecture, Civil Engineering and Geodesy (FACEG) who took a spatial ability test before and after attending the course. The results of the tests were then compared in order to determine whether their spatial abilities were improved and, if so, whether the mastering the course had an impact on it. The results showed significant difference among those three professions. The spatial ability test used in the research was customized for this purpose and will be described in the paper.
\end{abstract}

Keywords: descriptive geometry; engineering students; spatial abilities; spatial thinking

\section{INTRODUCTION}

The term spatial abilities appears in literature in several forms-spatial skills, spatial abilities, visual and spatial abilities etc., precisely because it implies, depending on the author, a wide range of different cognitive operations - from arranging cubes to map reading and spatial orientation. In relation to this, various authors have defined several factors that make up a set of spatial abilities (spatial perception, spatial visualization, mental rotations, spatial relations, spatial orientation [1]). Although various types of cognitive tasks that assess these spatial factors could be found in literature in the past half-century [2], the exact influence of those operations is still not determined.

Regardless of these factors, spatial abilities are recognized as essential for success in STEM fields (science, technology, engineering and mathematics), and various researches show that they are a key factor in the development of creativity and divergent thinking necessary in both technology and art related professions, such as architecture and civil engineering [3-6]. In one of this two decade long study $[7,8]$ it is shown that the spatial abilities could be the major predictor for creative, occupational, and life accomplishments of participants.

In psychological research a difference between spatial abilities and spatial skills has often been made. Spatial ability is defined as the innate ability to mentally manipulate spatial elements, that is, a person is born with such abilities. Spatial skills have been learned or acquired through some kind of formal or informal training. For students at the university level, it is almost impossible to distinguish between spatial abilities and spatial skills, because there is usually no formal training at lower education level in which students have the opportunity to acquire these skills. For most of them the first encounter with this subject is during the course of Descriptive Geometry at the first year of engineering studies.

The topic of improving spatial abilities is equally attractive both to psychologists and engineering educators. A large number of papers that investigate the possibility of improving spatial abilities by certain strategies or trainings can be found in literature. Those courses are supported by modern technologies [9], virtual reality [10], dynamic exercises, pen and paper exercises. Some authors are suspicious of the effects of spatial skills training [11], while others advocate it. The essence of these disagreements lies in the acceptance of spatial abilities as innate or acquired.

Many of those studies show that spatial skills could be developed over time, and that certain types of exercises can improve them [12-15]. Because of all above stated, it is important to continue further research on spatial abilities, its factors and influences on other scientific fields, and to determine if it is possible to develop them over time. If so, what are the right methods to do that, and what influence will they have on other occupations, specifically those concerning engineering?

In previous studies, spatial abilities were tested before and after the participants' engagement in some kind of spatial training (Descriptive Geometry, Digital modelling, Augmented reality course, Mathematics), but in most of them there were no control groups involved [9-15]. That means that it is not possible to accurately determine whether the training conducted by the researchers had an impact on improving spatial abilities, or it is caused by some other factor. In this research we choose Descriptive Geometry course as a tool to develop spatial abilities at two groups of students-the first group that took the course during the first semester (students of Civil Engineering and Geodesy), and the second one that did not (students of Architecture) at the Faculty of Architecture, Civil Engineering and Geodesy (FACEG) at the University of Banaj Luka.

While men and women do not differ in levels of general intelligence, gender differences do exist for more specific cognitive abilities. In particular, gender gaps in spatial ability are the largest of all gender differences in cognitive abilities. Research has shown that the development of spatial ability lays down the foundation for quantitative reasoning, a collective term for mathematical and science skills [16, 17]. For this reason, we also analyzed the progress of spatial skills based on gender.

This research has several goals. The first one is to contribute to the development of spatial tests with special review on spatial factors for engineering professions that would provide better insight in their assessments. Second 
one is to improve the current methodology of spatial ability assessments. The third one is to determine if Descriptive Geometry course held at the university has influence on developing students' spatial abilities.

This study provides empirical research in the area of spatial ability analysis of FACEG students with the aim of filling a gap in the literature that considers improving spatial abilities. This paper aims to answer the following research questions (RQs):

RQ1: What are the trends in improving spatial abilities?

RQ2: What relevant tools and teaching materials can be used to improve spatial abilities?

RQ3: Is there a correlation between the descriptive geometry course and the improvement of the spatial abilities of engineering students?

RQ4: What are other factors that could influence the level of spatial abilities?

RQ5: Are there gender differences in improving spatial abilities in engineering students?

To answer these questions, extensive literature was analyzed and a comprehensive study was conducted and is presented in the following sections of this paper.

The main research question of this paper relates to the impact of the Descriptive geometry course on spatial abilities of 175 students of FACEG that were tested with customized spatial ability tests.

\subsection{Spatial Tests and Spatial Factors}

The issue of standardized spatial tests is still an open topic in the field of psychology, most often because of the lack of researchers' consensus on factors that assess spatial abilities. There are many types of tasks that are used for assessing spatial abilities in literature, and the most common are The Mental Rotation Test (MRT), The Differential Aptitude Test: Space Relations (DAT: SR) and the Mental Cutting Test (MCT).

For the purposes of this research, we conducted a test that consisted of 4 types of tasks that had two levels of difficulty ( 8 tasks in total). The test was prepared by the teachers at the course using available literature on spatial ability tasks $[2,3,18,19]$. Three types of tasks required the ability to mentally manipulate objects (a, b, and d), while one type required the skill of the mental cutting (c).

These types require that:

(a) the respondent assumes the shape of the paper after folding-MRT (Fig. 1),

(b) the respondent recognizes the object after it has changed its position-MRT (Fig. 2),

(c) the respondent recognizes the shape of the section after an object has been cut with the plane-MCT (Fig. 3),

(d) the respondent recognizes the object based on its developed surface-DAT: SR (Fig. 4).
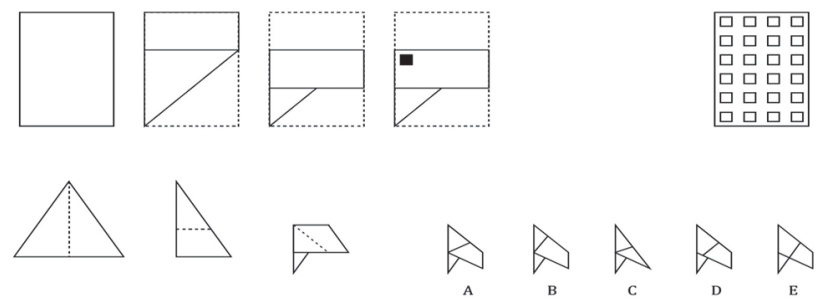

Figure 1 Type "a" - easy level (up) and advanced level (down)
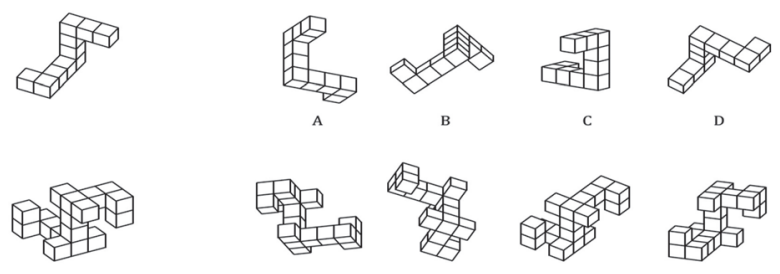

Figure 2 Type "b" - easy level (up) and advanced level (down)
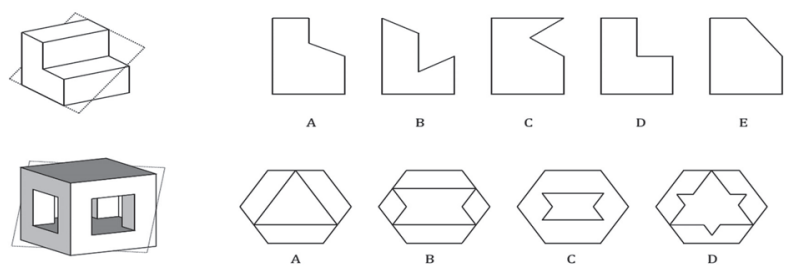

Figure 3 Type "c" - easy level (up) and advanced level (down)
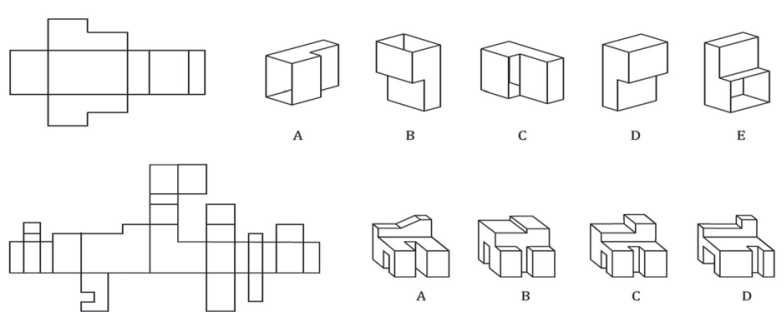

Figure 4 Type "d" - easy level (up) and advanced level (down)

The difficulty of tasks is caused by the specificity and requirements of the engineering professions where spatial abilities are recognized as essential for success, and candidates are expected to have higher than average level of spatial competence. Also, recent research suggests that spatial abilities develop creative thinking [20], which has been recognized as one of the main factors for success in the field of technology and innovation [21]. The diversity of tasks in the test is a result of the intention to determine which of the spatial ability factors has most potential to be improved by mastering the course of Descriptive geometry.

\section{RESEARCH METHODS AND ORGANIZATION}

The Descriptive geometry course takes place in the first semester at the department of Civil Engineering and Geodesy at the Faculty of Architecture, Civil Engineering and Geodesy at the University of Banja Luka (FACEG). This course takes 6 hours/week ( 2 hours of lectures +4 hours of theoretical assignments) and covers the following topics using traditional methods of Descriptive Geometry: general elements of projecting; point, line, plane and their mutual relations; transformation, rotation, intersections of lines, surfaces and solids both in isometric and orthogonal projection; roofs and terrain levelling. Theoretical assignments are executed with pen and paper, consisting of technically constructed drawings of mostly abstract and general elements such as lines and geometrical solids.

A total of 175 out of 212 students of the first year of the FACEG at the University of Banja Luka were included in the study, enrolled in the 2017/18 and 2018/19 academic years. Students took the spatial ability test at the beginning and at the end of the first semester. Each test contained a total of 8 tasks. The first four tasks were easier level tasks evaluated with 1 point each), and the other four were 
advanced level tasks evaluated with 2 points each). So, the maximum score on each test was 12 points. Also, the tasks were sorted according to the types described above. The test lasted 25 minutes. The first and the second test were not identical but had the same structure and task types. The tests were prepared by the teachers at the course.

For the statistical analysis we used the SPSS v.20 analytical-statistical software package, using descriptive statistics for presenting and summarizing data, the Paired Samples $t$-Test, nonparametric Mann-Whitney U test, and
Spearman's rank correlation coefficient. The variables observed in this study did not have normal distribution.

In the observed sample, the first group had 92 participants, while the second group had 83 participants (Tab. 1). There were 109 (62,3\%) female students and 66 $(37,7 \%)$ male students in total. The second group had higher percentage of female students $(75,9 \%)$, while the representation of male and female students in the first group was equal.

The average age of the sample was 19. Participants were not paid for taking part in the study.

Table 1The study sample by group and gender

\begin{tabular}{|c|c|c|c|c|c|}
\hline & & & \multicolumn{2}{|c|}{ GENDER } & \multirow[b]{2}{*}{ Total } \\
\hline & & & female & male & \\
\hline \multirow{8}{*}{ GROUP } & \multirow[t]{4}{*}{ G1 } & Count & 46 & 46 & 92 \\
\hline & & $\%$ within GROUP & $50,0 \%$ & $50,0 \%$ & $100,0 \%$ \\
\hline & & $\%$ within GENDER & $42,2 \%$ & $69,7 \%$ & $52,6 \%$ \\
\hline & & $\%$ of Total & $26,3 \%$ & $26,3 \%$ & $52,6 \%$ \\
\hline & \multirow[t]{4}{*}{ G2 } & Count & 63 & 20 & 83 \\
\hline & & $\%$ within GROUP & $75,9 \%$ & $24,1 \%$ & $100,0 \%$ \\
\hline & & $\%$ within GENDER & $57,8 \%$ & $30,3 \%$ & $47,4 \%$ \\
\hline & & $\%$ of Total & $36,0 \%$ & $11,4 \%$ & $47,4 \%$ \\
\hline \multirow{4}{*}{\multicolumn{2}{|c|}{ Total }} & Count & 109 & 66 & 175 \\
\hline & & $\%$ within GROUP & $62,3 \%$ & $37,7 \%$ & $100,0 \%$ \\
\hline & & $\%$ within GENDER & $100,0 \%$ & $100,0 \%$ & $100,0 \%$ \\
\hline & & $\%$ of Total & $62,3 \%$ & $37,7 \%$ & $100,0 \%$ \\
\hline
\end{tabular}

The specificquestions of this research were:

A. Does the mastering of Descriptive geometry have influence on the improvement of spatial abilities?

We compared the participants' scores of the first and second spatial tests in two groups of students: those who attended the DG course during the first semester (G1) and those who did not (G2). The first group (G1) consisted of first-year students of Civil Engineering and Geodesy, while the control group (G2) consisted of first-year students of Architecture.

The aim was to determine if there was any significant improvement in the level of spatial abilities in the group that attended the DG course in relation to the second group, and whether there was any significant improvement regarding gender.

After a general analysis of the results, the structure of the test was examined in more detail regarding the difficulty and task types in order to determine in which of the tasks students had most success, and whether there was progress in solving any particular type.

B. Does the high level of spatial ability have influence on mastering Descriptive Geometry?

The students' success in the course of Descriptive Geometry was measured by the total score during the semester. That included points earned in class and in two written colloquiums. We compared scores in both spatial ability tests with the final score in the course at the end of semester for the first group of participants. We also compared the scores by each task to determine whether some type of task has a correlation with success in the Descriptive Geometry.

\section{RESULTS AND DISCUSSION \\ 3.1 The Analysis of the Influence of Descriptive Geometry on Improving the Level of Spatial Abilities}

Tab. 2 shows the overall success of groups in the first and the second (control) test.
The Paired Samples $t$-Test showed a statistically significant difference in success between the first and second spatial ability tests in both groups $(t=-3,788, \mathrm{~d} f=$ 174, $p=0,000$ ). The second test had better score (Tab. 2).

Mann-Whitney U test showed a statistically significant difference in success in the first test between the first $(N=$ $92, M d=5,00)$ and the second group of students $(N=83$, $M d=7,00)$, where students of architecture (second group) achieved better score $(U=2561,00, Z=-3,771, p=0,000)$. Also, the same test showed the difference in success in the second test between the observed $(N=92, M d=6,00)$ and the control group of students $(N=83, M d=8,00)$, where students of architecture had more success again $U=$ 2057,00, $Z=-5,289, p=0,000)$.

Table 2 Overall success of groups in the first and the second (control) test

\begin{tabular}{|c|c|c|c|c|c|c|c|}
\hline & & $\mathrm{N}$ & 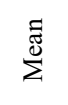 & $\begin{array}{l}\dot{\vec{D}} \\
\text { Dे } \\
\dot{\vec{D}}\end{array}$ & $\frac{\stackrel{\Xi}{\overparen{J}}}{\stackrel{0}{\Delta}}$ & Min. & Max. \\
\hline \multirow{3}{*}{ TEST 1} & G1 & 92 & 5,16 & 2,18 & 5,00 & 1,00 & 10,50 \\
\hline & G2 & 83 & 6,59 & 2,58 & 7,00 & 0,00 & 12,00 \\
\hline & Total & 175 & 5,84 & 2,47 & 6,00 & 0,00 & 12,00 \\
\hline \multirow{3}{*}{ TEST 2} & G1 & 92 & 5,59 & 2,82 & 6,00 & 0,00 & 12,00 \\
\hline & G2 & 83 & 7,91 & 2,50 & 8,00 & 2,50 & 12,00 \\
\hline & Total & 175 & 6,69 & 2,90 & 7,00 & 0,00 & 12,00 \\
\hline
\end{tabular}

Also, observing the average score for both groups in both tests, it is evident that the second group had better results in the second test compared to the first. Therefore, the second group of students had progressed more in spatial skills, even though they did not take the Descriptive Geometry course in the first semester.

These results lead to the conclusion that Descriptive Geometry contributed to the development of spatial abilities to some extent, but it is possible that some other courses and tasks that students of architecture take during the first semester (architectural design, architectural drawing, model making) had more influence on the development of their spatial abilities than Descriptive 
Geometry. It is also possible that the methodology of the Descriptive Geometry course requiring deductive, abstract and systematic cognitive processes is focused on developing spatial thinking rather than spatial abilities.

The difference in the initial level of spatial abilities among students of architecture compared to the students of civil engineering and geodesy can be justified with the entrance exam for architecture studies and the fact that due to the preparation for the entrance exam, students of architecture have undergone some training in spatial abilities before enrolment at the faculty. The main part of this exam consists of spatial perception and visualization test that includes various tasks for measuring spatial abilities.

Furthermore, another reason for the dominance of architecture students in spatial ability tests could be the distribution of students regarding their secondary school education. Students of all three study programs come from primarily two different secondary schools (grammar school and technical secondary school), but their distribution by study programs is not equal. Some technically oriented schools have the course of Descriptive Geometry in their curriculums. Tab. 3 shows the distribution of students by research groups in relation to whether they had previously dealt with the subject of Descriptive Geometry in secondary school.

Tab. 3 shows that in the first group $64,1 \%$ of the respondents had had the subject Descriptive Geometry in the secondary school, while in the second group this percentage is significantly lower $-38,6 \%$ and, despite this fact, the second group achieved better score on the spatial test.

Table 3 The distribution of students by study groups in relation to whether they had previously had the subject of Descriptive Geometry in secondary school

\begin{tabular}{|c|c|c|c|c|c|}
\hline & & & \multicolumn{2}{|c|}{ DG_sec.sch. } & Total \\
\hline & & & YES & $\mathrm{NO}$ & \\
\hline \multirow{8}{*}{ GROUP } & \multirow{4}{*}{ G1 } & Count & 59 & 33 & 92 \\
\hline & & $\%$ within GROUP & $64,1 \%$ & $35,9 \%$ & $100,0 \%$ \\
\hline & & \% within DG_sec.sch. & $64,8 \%$ & $39,3 \%$ & $52,6 \%$ \\
\hline & & $\%$ of Total & $33,7 \%$ & $18,9 \%$ & $52,6 \%$ \\
\hline & \multirow{4}{*}{$\mathrm{G} 2$} & Count & 32 & 51 & 83 \\
\hline & & $\%$ within GROUP & $38,6 \%$ & $61,4 \%$ & $100,0 \%$ \\
\hline & & \% within DG_sec.sch. & $35,2 \%$ & $60,7 \%$ & $47,4 \%$ \\
\hline & & $\%$ of Total & $18,3 \%$ & $29,1 \%$ & $47,4 \%$ \\
\hline \multirow{4}{*}{\multicolumn{2}{|c|}{ Total }} & Count & 91 & 84 & 175 \\
\hline & & $\%$ within GROUP & $52,0 \%$ & $48,0 \%$ & $100,0 \%$ \\
\hline & & \% within DG_sec.sch. & $100,0 \%$ & $100,0 \%$ & $100,0 \%$ \\
\hline & & $\%$ of Total & $52,0 \%$ & $48,0 \%$ & $100,0 \%$ \\
\hline
\end{tabular}

This suggests that Descriptive Geometry did not have a major impact on the development of spatial abilities with this group of students, at least in the case of a traditional approach in mastering this subject-with abstract tasks and theoretical application, as such methods develop spatial thinking, rather than spatial abilities. Unlike other professions, students of architecture and civil engineering specifically express the need for clear implementation of spatial solutions, which is the application of spatial abilities [11].

Tab. 4 shows that the majority of students of architecture are from grammar schools whereas in the study programs of Civil Engineering and Geodesy the majority of students are technical secondary school students. The advantage of pupils coming from grammar schools (schools with general oriented education), in relation to pupils of vocational secondary schools, also proved to be relevant in previous studies related to their success in entrance exams [22], where grammar school graduates had the highest average score in the test (Entrance exam), along with the highest average number of correctly solved tasks.

\subsubsection{Analysis by Types and Levels of Tasks}

Analyzing the results by types of tasks, Fig. 5 and Fig. 6 show that type d (DAT: SR) has the highest score in the first test for both groups, while type b (MRT) has the best score in the second test. Also, significant progress is evident for both mental rotation tasks (type a and type b), while the mental cutting tasks (type c) and the surface development tasks (type d) reveal a decrease in scores in both groups of respondents. Previous studies show that the mental rotation tasks develop a holistic approach where the timing of the tasks is important. The holistic strategy relies on visualizing the whole object, while the analytic strategy uses a systematic, stepwise approach $[15,23]$.

Table 4 The structure of students enrolled in different study programs in relation to secondary schools which they come from

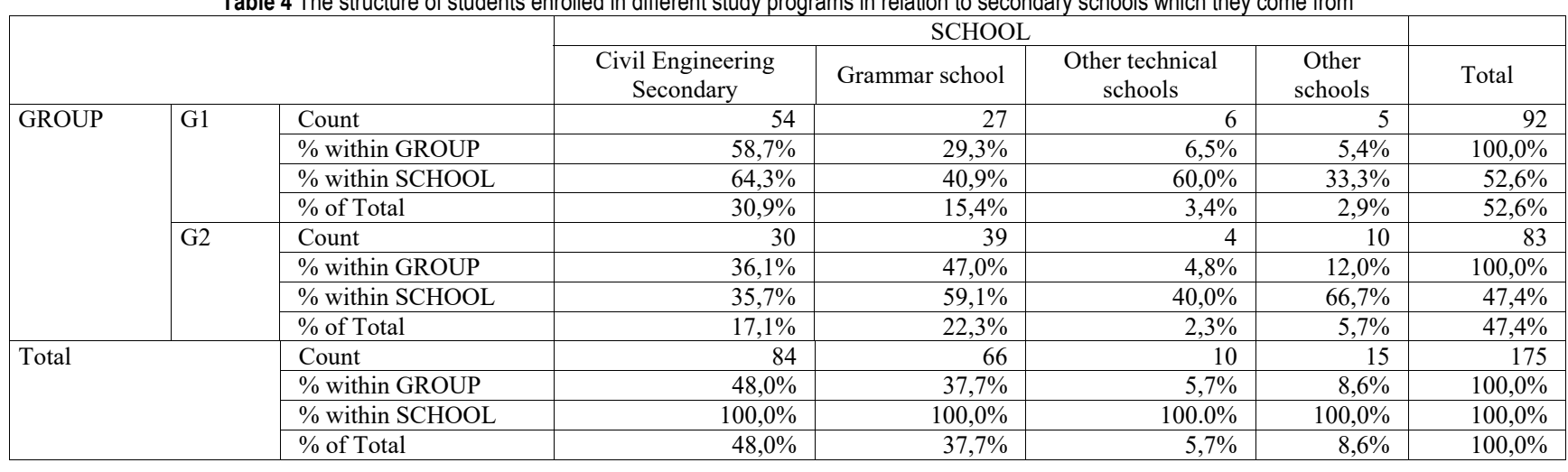


The general test results indicate that the level of spatial abilities in both men and women is medium. The average score achieved in the first test is 5,84, while in the second test it is 6,69 out of 12 points in total (Tab. 2). It should be taken into account that the test contained tasks of both basic and advanced level, which means that half of the tasks were considered to be above standard. However, if we look at the results by levels, Fig. 7 and the results of The Paired Samples $t$-Test $t=-6,376, \mathrm{~d} f=174, p=0,000)$ show that all participants had more success in solving advanced tasks in the second test compared to the first. Based on the results of The Paired Samples $t$-Test $(t=4,017, \mathrm{~d} f=174, p=$ $0,000)$, we conclude that lower-level tasks were poorly performed in the second test compared to the first one.

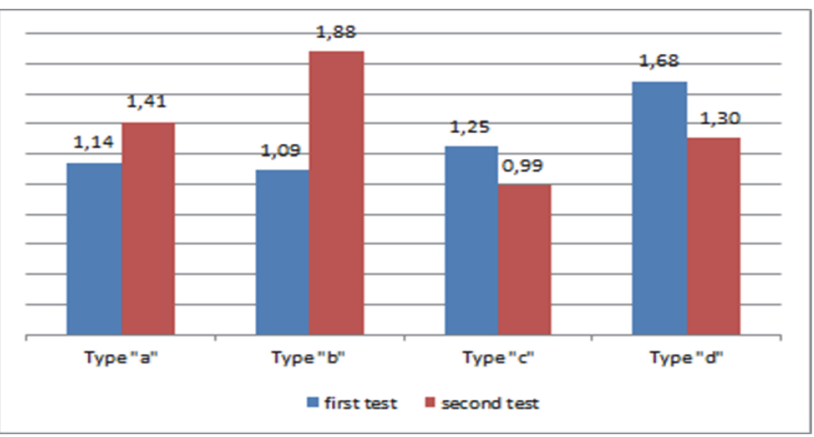

Figure $\mathbf{5}$ Scores by task types for the first group

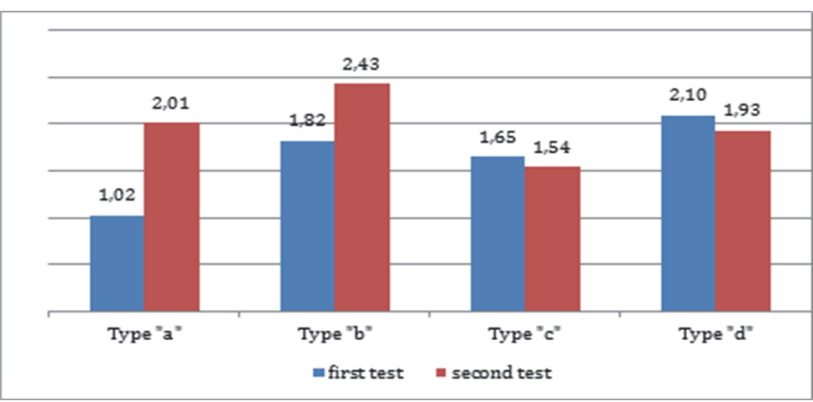

Figure 6 Scores by task types for the second group

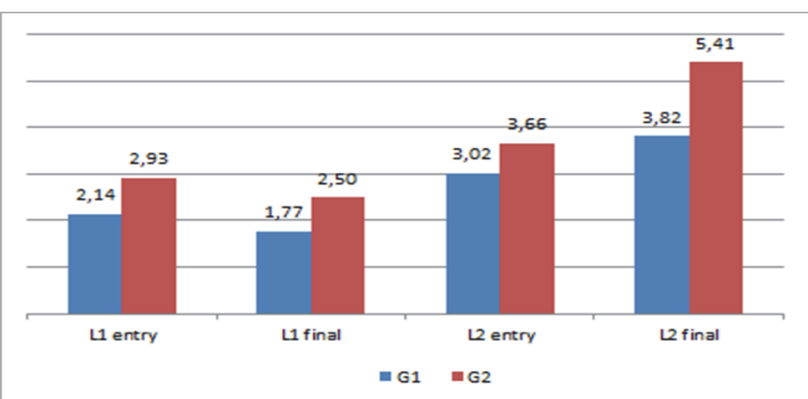

Figure 7 Comparison of basic (L1) and advanced (L2) level of tasks in the first and second test by groups $(\mathrm{G} 1, \mathrm{G} 2)$

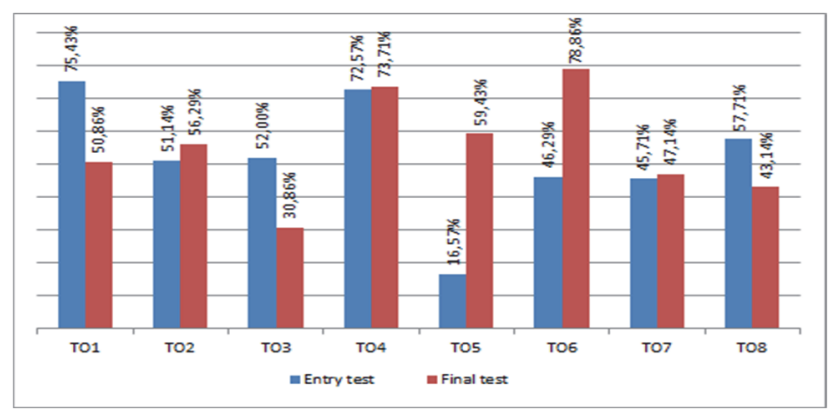

Figure 8 Percentage of success in solving tasks in both tests for all participants
Observing the whole sample, the most successfully solved task in the first test was task 1 (folding paper - basic level), while in the second test it was task 6 (mental rotation-level 1). The least successfully solved task in the first test was task 5 (folding paper-level 2), while in the second test it was task 3 (the mental cutting-level 1) (Fig. $8)$.

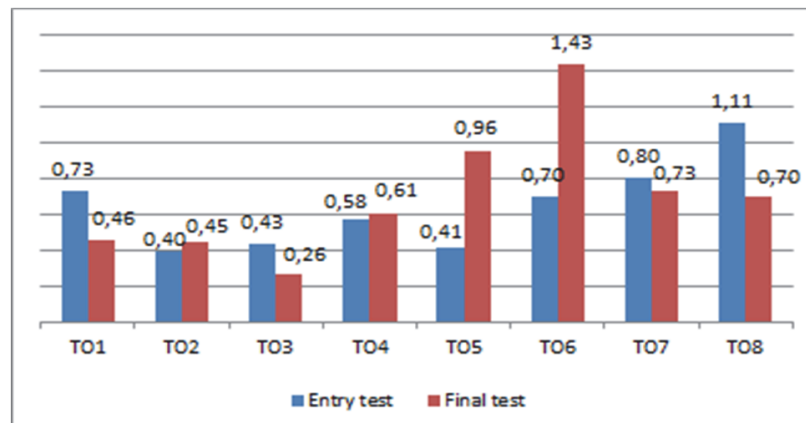

Figure 9 Score by tasks in the first (entry) and second (final) test for the first group

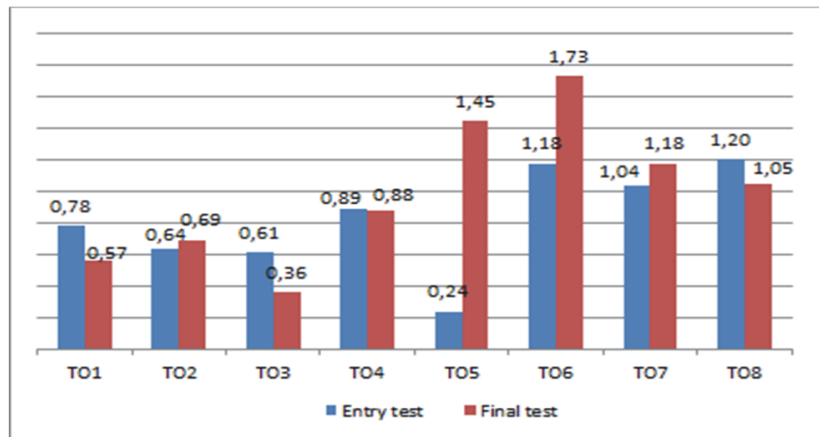

Figure 10 Score by tasks in the first (entry) and second (final) test for the second group

Fig. 9 and Fig. 10 show average scores by tasks for the first and second group of respondents. In the first group, observing the average points scored in both tests, the greatest progression is evident in task 6 (mental rotationlevel 1), while the greatest regression is shown in the eighth task 8 (surface development-level 2). In the second group, observing the average scores in both tests, the greatest progression is evident in task 5 (folding paper-level 2), while the greatest regression is shown in task 3 (mental cutting-level 1).

\subsubsection{Gender Differences}

\begin{tabular}{|c|c|c|c|c|c|c|c|}
\hline & & $\mathrm{N}$ & 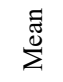 & 焉 & 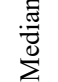 & Min. & Max. \\
\hline \multirow{3}{*}{ TEST 1} & $\mathrm{~F}$ & 109 & 5,75 & 2,46 & 6,00 & 1,00 & 12,00 \\
\hline & $\mathrm{M}$ & 66 & 5,98 & 2,52 & 6,00 & 0,00 & 10,50 \\
\hline & Total & 175 & 5,84 & 2,47 & 6,00 & 0,00 & 12,00 \\
\hline \multirow{3}{*}{ TEST 2} & $\mathrm{~F}$ & 109 & 6,69 & 2,91 & 7,00 & 0,00 & 12,00 \\
\hline & $\mathrm{M}$ & 66 & 6,69 & 2,93 & 6,50 & 0,00 & 12,00 \\
\hline & Total & 175 & 6,69 & 2,90 & 7,00 & 0,00 & 12,00 \\
\hline
\end{tabular}

The Paired Samples $t$-Test showed a statistically significant difference in the success between the first and the second tests in female students $(t=-3,707, \mathrm{~d} f=108, p$ $=0.000)$, while male students showed no statistically significant improvement in success in the second test $(t=$ 
$-1,653, \mathrm{~d} f=65, p=0,103)$. We conclude that female students are more likely than male students to improve spatial abilities (Tab. 5). Such results have also been shown in other studies concerning gender differences in spatial abilities [10, 24, 25] which report that women are progressing more during spatial ability trainings than men, as they have more space to evolve, given that they had lower spatial ability in the beginning.

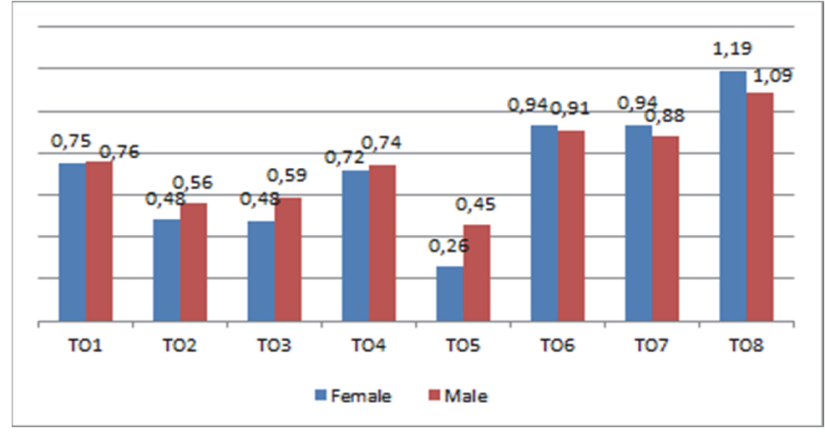

Figure 11Scores by tasks and gender in the first test

In the first test (Fig. 11), women showed slightly better results at the advanced level of tasks than men, while in both genders the score in basic level tasks was decreasing. The task in which women have shown better results in both tests is the task of folding paper-level 2. Generally, there are no major differences in gender regarding the task types.

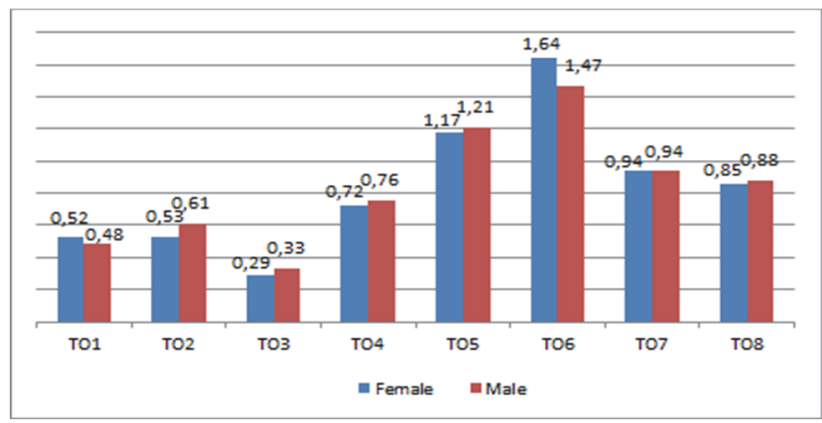

Figure 12 Scores by tasks and gender in the second test

\subsection{Correlation Between the Level of Spatial Abilities and Success in Descriptive Geometry}

Tab. 6 shows main positive correlations between success in test 2 and points scored from DG ( $r s=0,330)$, as well as between success in test 1 with success in test 2 $(r s=0,309)$.

A positive correlation of success in DG was obtained in task no. 2 - mental rotation $(r s=0.277)$ and task no. 4 surface development $(r s=0.357)$ in the first test, and with task no. $2(r s=0.286)$, no. $4(r s=0.266)$ and no. $6(r s=$ $0.307)$ in the second test.

This suggests that the factor of spatial manipulation has the biggest influence on mastering the course of Descriptive Geometry, that is, that the holistic approach has the greatest influence on solving abstract spatial problems [15].

\begin{tabular}{|c|c|c|c|c|c|}
\hline & & & TEST 1 & TEST 2 & DG \\
\hline \multirow[t]{7}{*}{ Spearman's rho } & \multirow[t]{3}{*}{ TEST 1} & Correlation Coefficient & 1,000 & $0,309^{* *}$ & 0,144 \\
\hline & & Sig. (2 - tailed) & - & 0,003 & 0,171 \\
\hline & & $\mathrm{N}$ & 92 & 92 & 92 \\
\hline & \multirow{3}{*}{ TEST 2} & Correlation Coefficient & $0,309^{* *}$ & 1,000 & $0,330^{* *}$ \\
\hline & & Sig. (2 - tailed) & 0,003 & - & 0,001 \\
\hline & & $\mathrm{N}$ & 92 & 92 & 92 \\
\hline & AK12 & $\begin{array}{l}\text { Correlation Coefficient } \\
\text { Sig. }(2 \text { - tailed }) \\
\text { N }\end{array}$ & $\begin{array}{c}0,144 \\
0,171 \\
92\end{array}$ & $\begin{array}{c}0,330^{*} \\
0,001 \\
92\end{array}$ & $\begin{array}{c}1,000 \\
- \\
92\end{array}$ \\
\hline
\end{tabular}

\section{CONCLUSION}

Based on the obtained results, it was concluded that mastering Descriptive Geometry improves spatial abilities to some extent. Most of all, it contributes to the improvement of mental manipulation factor, which develops a holistic approach to solving spatial problems. The methodology of Descriptive Geometry course requiring deductive, abstract and systematic cognitive processes is focused on developing spatial thinking more than spatial abilities.

An interesting fact is that students of architecture, who did not attend Descriptive Geometry course during this research, achieved better results in both tests of spatial abilities. After analyzing the structure of participants by study programs, it turned out that the students of architecture were mostly candidates who had general oriented education in secondary school, that is, they had not previously met with the subject of Descriptive Geometry. On the other hand, they did have a certain training in spatial ability before enrolment at the Faculty due to the entrance exam preparation.

Based on the results obtained, we can draw the following conclusions:

(1) Descriptive geometry develops spatial thinking, more than spatial abilities. Therefore, it is recommended to conduct an additional analysis of the possibility of inclusion/improvement of this course in the curriculum of architecture. This stems from the fact that, unlike other professions, architecture students especially express the need for a clear application of spatial solutions.

(2) Gender analysis showed negligible differences in the first spatial test. However, it has generally been shown that women have made greater progress in improving spatial abilities than men.

(3) Higher levels of spatial abilities, especially regarding the mental rotation factor, have a significant influence on mastering the Descriptive Geometry course, that is, on improving spatial abilities.

(4) Despite the differences between students in terms of the different study programs they have enrolled, it is 
evident that spatial skills tests are a relevant factor for architecture students. Therefore, one of the recommendations of this research is to further explore the specifics of the spatial abilities of this profession. This refers specifically to the connection and impact on the technical/artistic approach to solving spatial problems and possible strategies for developing these capabilities through further curriculum and practice, eg. regarding the new and yet promising field of architectural digitalisation and vizualisation.

\section{Acknowledgement}

This work is supported by the Project 19/6-020/961$47 / 18$ of the republic of Srpska Ministry of ScientificTechnological Development, Higher Education and Information Society.

\section{REFERENCES}

[1] Maresch, G. (2013). Raumintelligenz - Die Phasen der Raumintelligenzforschung.

[2] Ilic, M. \& Djukic, A. (2017). Typology of spatial ability tests and its implementation in architectural study entrance exams. Facta Univ.-Ser. Archit. Civ. Eng., 15(1), 1-14. https://doi.org/10.2298/FUACE161113001I

[3] Juščáková, Z. \& Górska, R. A. (2007). TPS Test Development and Application into Research on Spatial Abilities. J. Geom. Graph., 11(2), 223-236. https://doi.org/10.1017/S1359135500000725

[4] Leopold, C., Gorska, R., \& Sorby, S. (2001). Experiences in Developing the Spatial Visualization Abilities. J. Geom. Graph., 5(1), 81-91.

[5] Newcombe, N. S. (2010). Picture This: Increasing Math and Science Learning by Improving Spatial Thinking, American Educator, 2010. Am. Educ., 34(2), 29-35.

[6] Sorby, N. S. (2007). Developing 3D spatial skills for engineering students. https://doi.org/10.1080/22054952.2007.11463998

[7] Benbow, C. P., Bleske-Rechek, A., Lubinski, D., \& Webb, R. M. (2006). Tracking exceptional human capital over two decades. Psychol. Sci., 17(3), 194-199. https://doi.org/10.1111/j.1467-9280.2006.01685.x

[8] Lubinski, D. (2010). Spatial ability and STEM: A sleeping giant for talent identification and development. Pers. Individ. Dif., 49(4), 344-351. https://doi.org/10.1016/j.paid.2010.03.022

[9] Fleisig, R. V., Robertson, A., \& Spence, A. D. (2017). Improving the spatial visualization skills of first year engineering students. Proc. Can. Eng. Educ. Assoc.

[10] Kaufmann, H., Steinbügl, K., Dünser, A., \& Glück, J. (2005). General training of spatial abilities by geometry education in augmented reality. Annu. Rev. CyberTherapy Telemed. A Decad. VR, 3, 65-76.

[11] Uttal, D. H. \& Cohen, C. A. (2012). Spatial Thinking and STEM Education: When, Why, and How?. Psychol. Learn. Motiv., 57, 147-181. https://doi.org/10.1016/B978-0-12-394293-7.00004-2

[12] Burin, D. I. \& Delgado, A. R. (2000). Solution strategies and gender differences in spatial visualization tasks. Psicológica, 275-286.

[13] Wright, R., Thompson, W. L., Ganis, G., Newcombe, N. S., \& Kosslyn, S. M. (2008). Training generalized spatial skills. Psychon. Bull. Rev., 15(4), 763-771. https://doi.org/10.3758/PBR.15.4.763

[14] Baranová, L. \& Katreničová, I. (2018). Role of Descriptive geometry course in development of students' spatial visualization skills. Ann. Math. Informaticae, 49, 21-32. https://doi.org/10.33039/ami.2018.04.001

[15] Adanez, G. P. \& Velasco, A. D. (2004). Training visualization ability by Technical Drawing. J. Geom. Graph.

[16] Yoon, S. Y. \& Mann, E. L. (2017). Exploring the Spatial Ability of Undergraduate Students: Association With Gender, STEM Majors, and Gifted Program Membership," Gift. Child Q., 61(4). https://doi.org/10.1177/0016986217722614

[17] Reilly, D., Neumann, D. L., \& Andrews, G. (2017). Gender Differences in Spatial Ability: Implications for STEM Education and Approaches to Reducing the Gender Gap for Parents and Educators. in Visual-spatial Ability in STEM Education, Cham: Springer International Publishing, 195224. https://doi.org/10.1007/978-3-319-44385-0 10

[18] Eliot, J. \& Smith, I. M. (1983). An international directory of spatial tests. NFER-Nelson.

[19] Ilić, M. \& Stavrić, M. (2014). Developing spatial ability for quality engineering education. 16th Int. Conf. Geom. Graph.

[20] Kell, H. J., Lubinski, D., Benbow, C. P., \& Steiger, J. H. (2013). Creativity and Technical Innovation. Psychol. Sci., 24(9), 1831-1836. https://doi.org/10.1177/0956797613478615

[21] Baillie, C. \& Walker, P. (2007). Fostering Creative Thinking in Student Engineers," Eur. J. Eng. Educ., 23(1), 35-44. https://doi.org/10.1080/0304379980230105

[22] Preradović, L. (2015). Student achievement in the university entrance examination and the effects of preparation classesa case study of civil engineering students. Teh. Vjesn. Gaz, . https://doi.org/10.17559/TV-20140513114019

[23] Gluck, J. \& Fitting, S. (2003). Spatial Strategy Selection: Interesting Incremental Information. Int. J. Test., 3(3), 293308. https://doi.org/10.1207/S15327574IJT0303_7

[24] Sorby, S. (2007). Developing 3D spatial skills for engineering students. Australas. J. Eng. Educ., 13(1), 1-11. https://doi.org/10.1080/22054952.2007.11463998

[25] Terlecki, M. S., Newcombe, N. S., \& Little, M. (2008). Durable and generalized effects of spatial experience on mental rotation: Gender differences in growth patterns," Appl. Cogn. Psychol. Off. J. Soc. Appl. Res. Mem. Cogn., 22(7), 993-1013. https://doi.org/10.1002/acp.1420

\section{Contact information:}

Maja ILIĆ, PhD, Assistant professor

(Corresponding author)

University of Banja Luka, Faculty of Architecture, Civil Engineering and Geodesy,

Stepe Stepanovića 77/3, Banja Luka, Bosnia and Herzegovina,

E-mail: maja.ilic@aggf.unibl.org

Sandra KOSIĆ-JEREMIĆ, PhD, Assistant professor

University of Banja Luka, Faculty of Architecture, Civil Engineering and Geodesy,

Stepe Stepanovića 77/3, Banja Luka, Bosnia and Herzegovina,

E-mail: sandra.kosic.jeremic@aggf.unibl.org

Milena STAVRIĆ, PhD, Full professor

TU Graz, Institute of Architecture and Media,

Kronesgasse 5/III, Graz, Austria

E-mail: mstavric@tugraz.at 